\title{
Small and Medium Enterprises and Inclusive Growth in the Globalisation Era
}

\author{
*Dr. S.Shahina Begum, M.Com., Ph.D., \\ *Associate Professor, Accord MBA College, Chiguruvawada Tirupati
}

\begin{abstract}
Micro, Small and Medium Enterprise (MSME) sector has been undergoing a metamorphosis in the era of globalisation for over a decade and a half. Many developments of relevance to SMEs (Small and Medium Enterprises) have taken place within the country and internationally. Globalisation resulting in fierce competition in various product lines has forced the SME sector to adopt strategies in tune with the global trends. A number of programmes of cluster-specific and firm-specific approaches are being pursued by all India organisations with a wide network of institutions associated with various functions supporting the SME sector at different levels. The paper reviews the progress of MSME sector from 2000-01 in particular, and discusses a few key approaches adopted in the sector. These include the following: Eleventh and Twelfth Plan approaches for inclusive growth, MSMED Act 2006, credit flow to MSMEs, policy of de-reservation, greater equity participation, cluster development approach (CDA), National Manufacturing Competitiveness Programme (NMCP), Central Public Procurement Policy (CPPP) and Defence Production Policy, Development of employment-intensive enterprises, employment generation programmes for micro enterprises promotion, and training and entrepreneurship development. Conclusion and Suggestions are offered towards the end of the paper. The four appendices given include websites of MSME and related organisations, and particulars of web portals of National Small Industries Corporation (NSIC), and call centres set up by NSIC and Union Ministry of MSME.
\end{abstract}

Key Words: MSME, Gobalisation, Cluster, Growth performance, Exports etc.,

\section{Inclusive Growth and Financial Inclusion ${ }^{1}$}

Defined in the Eleventh Five Year Plan (2007-12) as a "growth process which yields broad-based benefits, and ensures equality of opportunity for all", "inclusive growth" stands for "equitable development" or "growth with social justice", which have always been the watchwords of development planning in the country. There is now a genuine and widespread recognition about the adverse social consequences of rising inequalities in the recent high growth phase, which do not seem to be mitigated through the so called "trickle down" mechanism. With the GDP growth rate rising from 7\% to $8 \%$, and around $9 \%$ per annum, rural-urban divide, regional divide, and rich-poor divide have become glaring, which brought "inclusive growth" high on the policy agenda.

It is not inevitable that growth in GDP should lead to a rise in inequalities in income - whether before or after the reforms. Much depends on the level and spatial distribution of physical infrastructure, human resource development, prevailing social structure, social policies, and governance patterns. Inadequate physical and social infrastructure like irrigation, power, roads, transport and communications, education and health in the less developed regions, and rural areas in general in the country is a major factor responsible for the growing rural-urban, and regional disparities. This is also responsible for the slow growth of manufacturing and other activities in the rural non-farm sector, which explains the slow shift of the labour force from agriculture; and hence slow reduction in rural poverty. The highly stratified and hierarchical social structure characterised by inequalities in land holdings and other forms of wealth, status, and power is the second major factor leading to rise in income inequalities in the wake of growth. Because of this, achieving inclusive growth is far more challenging than stepping up the GDP growth rate. Finally, the governance pattern, that is, the working of our democracy under the prevailing social structure, and the efficiency of implementation mechanisms or delivery systems, determines the actual outcomes on the ground from our planning exercises and policies.

The World Bank has defined inclusive growth as that which equals economic growth, while sharing the benefits of growth to reduce poverty. Inclusive growth as a development strategy has been quite successful in East Asia, where economic development has benefited the poor and the non-poor. This should prove equally relevant to India. Inclusive growth becomes an important agenda in India in view of the high growth numbers in recent years, and the need for distribution of economic benefits to the wider spectrum of people. Inclusive growth has emerged as an important development priority; and banks being the major financial intermediaries in

${ }^{1}$ Hanumantha Rao, C.H. (2009), "Inclusive Growth: Recent Experience and Challenges Ahead", Economic and Political Weekly, Vol. 44 No. 13, March 28, pp.16-21. 
the growth process, it becomes imperative that they too engage actively in promoting sustainable development strategies of inclusive growth.

Financial inclusion means providing access through appropriate financial products and services to individuals $^{2}$. It means delivery of financial products - deposits and loans - and other services to the needy and poorer sections of the society at affordable cost. Financial inclusion rests on three pillars, viz., access, affordability, and actual utilisation of financial services. Financial inclusion can be achieved only if all the three pillars show affirmative results. Banks being commercial institutions, financial inclusion would appeal to them only if giving a loan to any person or maintaining deposit account of a person makes business sense. To make it more attractive, we need to focus on reducing the transaction cost in the delivery of products and services by extensive use of low cost technology so that they become affordable to the weaker sections of the society. We cannot think of reducing the transaction cost without appropriate use of technology. Creation of adequate infrastructure in rural areas is a requirement without which our efforts in achieving inclusive growth will be unsuccessful. Besides physical accessibility, availability of power, etc., electronic connectivity of remote areas is a must. It is generally agreed that for taking banking services into rural interiors, we will need to rely on Information and Communication Technology (ICT) channels. Availability and reliability of telecom connectivity would, therefore, be crucial for our mission.

\section{Twelfth Plan Approach to Inclusive Growth ${ }^{3}$}

The Eleventh Five Year Plan (2007-12) aimed at achieving faster and more inclusive growth. The Twelfth Plan (2012-17), as indicated in its Approach paper of November 2011 focuses on continuing the momentum, and pursuing faster, sustainable and more inclusive growth. Inclusiveness is a multidimensional concept. It refers to broad spread of benefits to all sections of population, particularly scheduled castes, scheduled tribes, backward classes, and other marginalised groups, and also protecting the environment. Nobel Laureate Amartya Sen refers to India as a fast growing economy with limited results in terms of broadbased social progress. Inclusive growth should result in lower incidence of poverty, broad-based and significant improvement in health outcomes, universal access for children to school, increased access to higher education, and improved standards of education, including skill development. It should also be reflected in better opportunities for both wage employment and livelihood, and in provision of basic amenities to all sections of people, with focus on vulnerable and marginalised groups. During the Eleventh Plan, awareness about inclusiveness and empowerment amongst people has been generated. A greater desire to access information about the rights and entitlements made available by law and policy, and eagerness to demand accountability from the public delivery systems augurs well for the future. Along with reduction in the percentage of population below the poverty line, it is important to address concerns about growing inequalities among various sections of people, and in different regions, including districts within a State.

Sector-wise analysis with focus on inclusiveness lays greater reliance on agriculture and crucial social sectors. Emphasis is also on strengthening institutions and delivery mechanisms that take the benefits of high growth to the poor. For major flagship programmes of the Government, greater focus will be on issues of implementation and governance to improve their effectiveness. With the overall GDP growth during the 12th Plan (2012-17) targeted at 9 per cent per annum as indicated in the Approach Paper, growth rates envisaged for the individual sectors are as follows: agriculture $4 \%$, industry $9.6 \%$, services $10 \%$, and manufacturing $9.8 \%$. The GDP growth rate for the 12th Plan has since been revised to $8 \%$ in the National Development Council meeting held in early December 2012. National Manufacturing Policy (NMP) (2011) seeks to achieve inclusive growth of the economy by implementing cohesive policy measures for creating the state-of-the art manufacturing facilities; and it assigns a prominent role for micro, small and medium enterprises in promoting inclusiveness. The NMP seeks to enhance the share of manufacturing in GDP to at least 25 per cent within a decade by 2022 from the present level of around 16 per cent, a level that has been stagnant since 1980, and enhance the global competitiveness of the sector. Besides, it focusses on domestic value additon, technological depth, and environmental sustainability of growth. The Policy envisages creation of 100 million additonal jobs by 2022 , and creation of appropriate skill sets among the rural migrant and urban poor to make growth inclusive. National Manufacturing Competitiveness Programme (NMCP) is an important direction to strengthen the competitve ability of enterprises through specific components of the programme. Effectiveness of the measures is dependent on innovative approaches adopted at various stages of the enterprise development cycle. Governments, private sector and NGOs (voluntary sector) have a key role to play in devising relevant interventions at specific stages appropriately, and to ensure meaningful results. There should be a new thrust on innovation and local economic

${ }^{2}$ Chakrabarty, K.C. (2011), "Financial Inclusion and Banks - Issues and Perspectives," RBI Monthly Bulletin, November, pp.1831-1837.

${ }^{3}$ Government of India, Planning Commission (November 2011), Faster, Sustainable and more Inclusive Growth - an Approach to the Twelfth Five Year Plan (2012-17), New Delhi. 
development with focus on intellectual property rights (IPRs). Public-private partnership should take a new form for implementing these approaches. A synergy of several components, such as Business Development Services (BDS), new financial products, innovation, communication, and an ecosystem approach to development are vital.

\section{MSMED Act, 2006}

The Micro, Small and Medium Enterprises Development (MSMED) Act has become operational from October 2006. Being a comprehensive legislation for the promotion, development, and enhancement of competitiveness of the MSME sector, a number of measures were provided in the Act for enhancing competitiveness of SMEs, and for enabling the enterprises to avail the benefits of global markets.

Under the Act, the enterprises have been categorised into those engaged in (i) manufacturing, and (ii) providing / rendering of services. Both categories have been further divided into micro, small and medium enterprises, based on their investment in plant and machinery (for manufacturing) or in equipment (in case of service enterprises) as shown in Table 1.

Table 1: Classification of MSMEs by Investment Limit(in Rs. million)

\begin{tabular}{|l|l|l|}
\hline Category of Enterprise & Manufacturing (in plant \& machinery) & Service (in equipment) \\
\hline Micro & up to 2.5 & up to 1.0 \\
\hline Small & 2.5 to 50 & 1 to 20 \\
\hline Medium & 50 to 100 & 20 to 50 \\
\hline
\end{tabular}

Source: Government of India (2006), MSMED Act, 2006.

The Act provides for a statutory consultative mechanism at the national level with wide representation of all stake-holders, and an advisory committee to assist the National Board and the Centre and State governments. The other features include: (i) establishment of specific funds for the promotion, development and enhancement of competitiveness of these enterprises, (ii) notifications of schemes / programmes for this purpose, (iii) progressive credit policies and practices, (iv) preference for government procurement to products and services of micro and small enterprises, (v) problem of delayed payments to MSEs, and also (vi) simplification of the process of closure of business by all the three categories of enterprises.

\section{Growth of Micro, Small and Medium Enterprises}

Micro, Small and Medium Enterprise (MSME) sector, also known as Small and Medium Enterprise (SME) sector has a prominent role to play in ensuring that growth is inclusive and regionally balanced. In the context of liberalisation from 1991, the sector has been integrating itself with globalisation and global trends in a phased manner as part of the overall strategies adopted for industry and trade at the national level. It has been steadily reorienting itself to face the challenges posed by increased competition, domestically and internationally. SMEs with their dynamism, flexibility and innovative spirit will have to adapt themselves to the fast changing needs of the market-driven economy, where the Government acts as a facilitator and promoter, no longer as a regulator. The strategies evolved in recent years, from 2000 in particular, are to help the sector to become globally competitive, and graduate from micro to small, small to medium, and from medium to large. Advanced manufacturing techniques and management practices can be sourced and adopted with greater ease. As participants in the global value chain, the SMEs can gain entry into larger avenues, expand their markets, find new niche markets for their products, and become prominent in the global arena with "Made in India" brand. Gainful participation in the global value chain can be used as a strategic measure for SME development. Despite competition from large enterprises, SMEs certainly have the potential to enter global value chains provided they adapt to the market shifts globally.

The liberalisation policies of the government provide the small and medium enterprises challenges and opportunities. The challenges arise in the form of competition and reduced protection, whereas opportunities arise in the form of better technology, scope for technical collaborations, availability of a variety of raw materials and components through global sourcing, guaranteeing better quality and means of higher efficiency and productivity. The major landmarks in the growth of small and medium enterprises in the country in recent years are : January 1995 - founding of the World Trade Organisation (WTO - with the conversion of GATT General Agreement on Tariffs and Trade), with India as a founder member of the organisation; April 2001 dismantling of quantitative restrictions virtually totally permitting liberal imports; and January 2005 - expiry of the ten-year period of the multifibre agreement in context of textile exports. All the three stages led to fierce competition to SMEs within the country and abroad. SMEs have been undergoing rapid and fundamental changes in tune with international currents. With the advent of the new economic policy, it was felt that the small-scale sector would not be able to face the onslaught of competition from large industrial units in the domestic as well as international markets. However, it was proved that these apprehensions were unwarranted. 
As a matter of fact, the small-scale sector was able to put up a spectacular performance in the period of economic liberalisation. Performance of the small-scale sector was much better than the manufacturing sector as a whole. At this juncture, it would be worthwhile to study the progress of the sector after the introduction of the new economic policy.

Table 2 presents the real growth rate of GDP (Gross Domestic Product), and Index of Industrial Production for industry as a whole, manufacturing, and micro and small enterprise sector for the country. Tables $3 \& 4$ present the performance of micro, small and medium enterprises in terms of number of units (registered and unregistered), fixed investment, production at current prices, employment, and exports at current prices for all India. Table 5 presents the total merchandise exports for the country and exports of MSE products in US \$ terms at current prices. All the three tables also present simple annual growth rate for all the years. Total period covered in the tables is 2000-01 to 2012-13. CAGR (compound annual growth rate) has been worked out for specified periods.

Table 2: Real Growth Rates of GDP \& Index of Industrial Production (2000-13) (in per cent)

\begin{tabular}{|c|l|l|l|l|}
\hline Year & Real GDP & $\begin{array}{c}\text { Total } \\
\text { Industry }\end{array}$ & \multicolumn{1}{|c|}{ Manufacturing } & MSE Sector \\
\hline $\mathbf{1}$ & $\mathbf{2}$ & $\mathbf{3}$ & \multicolumn{1}{c|}{$\mathbf{4}$} \\
\hline $2000-01$ & 4.4 & 5.0 & 5.3 & $\mathbf{5}$ \\
\hline $2001-02$ & 5.8 & 2.7 & 2.9 & 6.1 \\
\hline $2002-03$ & 3.8 & 5.7 & 6.0 & 8.7 \\
\hline $2003-04$ & 8.5 & 7.0 & 7.4 & 9.6 \\
\hline $2004-05$ & 7.5 & 8.4 & 9.2 & 10.9 \\
\hline $2005-06$ & 9.5 & 8.0 & 8.9 & 12.3 \\
\hline $2006-07$ & 9.6 & 12.9 & 15.0 & 12.6 \\
\hline $2007-08$ & 9.3 & 15.5 & 18.4 & 13.0 \\
\hline $2008-09$ & 6.7 & 2.5 & 2.5 & 13.1 \\
\hline $2009-10$ & 8.6 & 5.3 & 4.8 & 13.7 \\
\hline $2010-11$ & 9.3 & 8.2 & 8.9 & 13.6 \\
\hline $2011-12$ & 6.2 & 2.9 & 3.0 & n.a. \\
\hline $2012-13$ & $5.0 *$ & n.a. & n.a. \\
\hline
\end{tabular}

Notes: Growth rates mentioned above for Index of industrial production for industry and manufacturing are at 1993-94 prices up to 2005-06, and from 2006-07 at 2004-05 prices. In respect of real GDP, growth rates are at 2004-05 prices from 2005-06; and for earlier years at 1999-2000 prices; \& for MSE (micro and small enterprises) Sector at 2001-02 prices. * Advance estimate

Sources: 1. Union Ministry of Finance, Economic Division (2013), Economic Survey 2012-13, and earlier issues from 2000-01, New Delhi. Available at http://indiabudget.nic.in

2.Reserve Bank of India (2012), Annual Report 2011-12, Mumbai. Available at www.rbi.org.in

Table 3: Performance of MSMEs as per the Fourth Census of MSMEs and Economic Census (2006-12)

\begin{tabular}{|c|c|c|c|c|c|}
\hline Year & $\begin{array}{c}\text { Number of MSMEs (regd. \& } \\
\text { unregd. - cumulative) } \\
\text { (millions) }\end{array}$ & $\begin{array}{c}\text { Fixed } \\
\text { investment } \\
\text { (Rs. Billion) }\end{array}$ & $\begin{array}{l}\text { Production at } \\
\text { current prices } \\
\text { (Rs. billion) }\end{array}$ & $\begin{array}{c}\text { Employment } \\
\text { (millions) }\end{array}$ & $\begin{array}{l}\text { Exports at } \\
\text { current prices } \\
\text { (Rs. billion) }\end{array}$ \\
\hline 1 & 2 & 3 & 4 & 5 & 6 \\
\hline $2006-07$ & 36.18 & 8685 & 13514 & 80.52 & $1825.38(21.5)$ \\
\hline $2007-08$ & $37.74(4.3)$ & $9174(5.6)$ & $14352(6.2)$ & $84.22(4.6)$ & $2020.17(10.7)$ \\
\hline $2008-09$ & $39.37(4.3)$ & $9714(5.9)$ & $15242(6.2)$ & $88.11(4.6)$ & n.a. \\
\hline $2009-10$ & $41.08(4.3)$ & $10293(6.0)$ & $16194(6.2)$ & $92.22(4.7)$ & n.a. \\
\hline $2010-11$ & $42.88(4.3)$ & $10949(6.4)$ & $17216(6.3)$ & 96.57 (4.7) & n.a. \\
\hline $2011-12$ & 44.77 (4.4) & $11769(7.5)$ & $18343(6.5)$ & $101.26(4.9)$ & \\
\hline
\end{tabular}

Notes:

1. Figures in parentheses indicate percentage variation over the previous year.

2. One billion equals 1000 million or 100 crores.

3. Results of the Fourth All India Census on MSMEs (reference year 2006-07) and Economic

Census 2005, have been used for working out projections for the years from 2007-08 as mentioned in the above table.

Sources: Union Ministry of Micro, Small and Medium Enterprises (2013), Annual

Report 2012-13, New Delhi. Available at www.msme.gov.in 
Table 4: Size of the MSME Sector $\left(4^{\text {th }}\right.$ Census of MSMEs and Economic Census 2005) (Reference year: 2006-07)

\begin{tabular}{|c|l|l|l|l|c|}
\hline $\begin{array}{c}\text { Sl. } \\
\text { No. }\end{array}$ & \multicolumn{1}{|c|}{ Particulars } & \multicolumn{1}{|c|}{ Regd. Sector } & Un-regd. Sector & EC 2005 & Total \\
\hline $\mathbf{1}$ & \multicolumn{1}{|c|}{$\mathbf{2}$} & \multicolumn{1}{|c|}{$\mathbf{3}$} & $\mathbf{4}$ & $\mathbf{5}$ & $\mathbf{6}$ \\
\hline 1 & $\begin{array}{l}\text { Size of the sector-No.of } \\
\text { enterprises - lakhs }\end{array}$ & 15.64 & 198.74 & 147.38 & 361.76 \\
\hline 2 & $\begin{array}{l}\text { No. of rural enterprises - lakhs } \\
(\%)\end{array}$ & $7.07(45.2)$ & $119.68(60.2)$ & $73.43(49.8)$ & $200.18(55.3)$ \\
\hline 3 & $\begin{array}{l}\text { No. of women enterprises - lakhs } \\
(\%)\end{array}$ & $2.15(13.7)$ & $18.06(9.1)$ & $6.4(4.3)$ & $26.61(7.4)$ \\
\hline 4 & Total employment - lakhs & 93.09 & 408.84 & 303.31 & 805.24 \\
\hline
\end{tabular}

Notes: 1. EC 2005: Economic Census 2005 was carried out by the Central Statistical Organisation (CSO) of the Union Ministry of Statistics and Programme Implementation. Data extracted from EC 2005 given in the above table include activities of wholesale / retail trade, legal, education and social services, hotels and restaurants, transports, and storage and warehousing (except cold storage).

2, Figures in parentheses in rows 2 and 3 indicate percentage to the respective column totals as given in row 1 . Source: ibid.

Table 5: Exports from Micro and Small Enterprises (MSEs) in Relation to Total Merchandise Exports (2000-13) (at current prices)

\begin{tabular}{|c|c|c|c|c|c|}
\hline Year & $\begin{array}{l}\text { Total Exports } \\
\text { (US \$ billion) }\end{array}$ & $\begin{array}{l}\text { Exports of MSE } \\
\text { products (US \$ } \\
\text { billion) }\end{array}$ & $\begin{array}{l}\text { \% share of } \\
\text { MSE in total } \\
\text { exports }\end{array}$ & $\begin{array}{c}\text { Growth of } \\
\text { MSE Exports } \\
(\%)\end{array}$ & $\begin{array}{c}\text { Growth of total } \\
\text { exports (\%) }\end{array}$ \\
\hline 1 & 2 & 3 & 4 & 5 & 6 \\
\hline $2000-01$ & 44.56 & 15.28 & 34.3 & 22.1 & 21.0 \\
\hline 2001-02 & 43.83 & 14.94 & 34.1 & -2.2 & -1.6 \\
\hline $2002-03$ & 52.72 & 17.77 & 33.7 & 18.9 & 20.3 \\
\hline 2003-04 & 63.84 & 21.25 & 33.3 & 19.6 & 21.1 \\
\hline 2004-05 & 83.54 & 27.69 & 33.1 & 30.3 & 30.8 \\
\hline 2005-06 & 103.09 & 33.94 & 32.9 & 22.6 & 23.4 \\
\hline $2006-07$ & 126.41 & 40.36 & 31.9 & 18.9 & 22.6 \\
\hline $2007-08$ & 163.13 & 50.25 & 30.8 & 24.5 & 29.0 \\
\hline 2008-09 & 185.30 & n.a. & n.a. & n.a. & 13.6 \\
\hline $2009-10$ & 178.75 & n.a. & n.a. & n.a. & $(-) 3.5$ \\
\hline $2010-11$ & 251.14 & n.a. & n.a. & n.a. & 40.5 \\
\hline 2011-12 & 305.96 & n.a. & n.a. & n.a. & 21.8 \\
\hline $2012-13$ & 300.57 & n.a. & n.a. & n.a. & $(-) 1.8$ \\
\hline
\end{tabular}

Source: Union Ministry of Finance, Economic Division (2013), Economic Survey 2012-13,

and earlier issues from 2000-01, New Delhi. Available at http://indiabudget.nic.in

The above tables reveal the tremendous growth of the small scale sector during the post-liberalisation period, which was launched in July 1991. Two years 1995-96 and 1996-97 recorded the higher growth rate of real GDP at 1999-2000 prices beyond 7 per cent. Again in 2003-04, 8.5 per cent growth rate has been recorded. It may be mentioned that the high growth rate of 8.5 per cent in 2003-04 is over the low growth figure of 3.8 per cent in the previous year. Hence, this can not be considered as very high level of achievement. During 2004-05, 2005-06, and 2006-07, growth rate was 7.5, 9.5, and 9.6 per cent, respectively, over the high growth rate of 8.5 per cent of 2003-04. For 2007-08, it is assessed as 9.3 per cent. Despite the global meltdown, and the resultant dismal performance of the manufacturing sector, Indian economy managed to record 6.7 per cent growth of GDP in 2008-09.

In the next two years, 2009-10 and 2010-11, the growth rate recorded was 8.6 per cent, and 9.3 per cent, respectively which is an indication of the gradual process of recovery. In 2011-12, the growth rate fell to 6.2 per cent, with the last quarter of the year touching a low of 5.3 per cent. In 2012-13, advance estimate indicates GDP growth rate of 5,0 per cent. Deceleration in industrial production from the supply side, and weak investment demand from the demand side, have in particular, contributed to the slow down. The five years from 2003-04 to 2007-08 have recorded the highest growth rate in the recent periods, followed by 2009-10 and 201011. Compound annual growth rate of GDP for 1995-96 to 2005-06 is 6.5 per cent with break up of 5.9 per cent up to 2000-01, and 7.0 per cent from 2000-01. The average growth rate achieved during the last four years of the Tenth Plan (2003-07) is 8.8\%, and for the entire Plan period (2002-07) 7.8\%, very close to the targeted $8 \%$. After a sharp recovery from the global financial crisis and two successive years of robust growth of 8.6 per cent and 9.3 per cent, GDP growth decelerated sharply to a nine-year low of 6.2 per cent during 2011-12, and is likely to decline further to 5.0 per cent in 2012-13. The slowdown was reflected in all sectors of the economy but the industrial sector suffered the sharpest deceleration. In the Eleventh Plan period (2007-12), the average growth rate achieved is 7.9 per cent. MSE sector production growth rate has been moving upwards steadily, and 
consistently higher than that of industry as a whole and manufacturing, except in 1995-96, 2006-07, and 200708. This demonstrates a high degree of resilience and adaptability of the MSME sector. The growth rate has been steady, though there were ups and downs. It has been 10.0 per cent and above from 2004-05. Growth rate (CAGR) during 1995-96 to 2005-06 works out to 8.6 per cent with break up of 8.7 per cent in the first half up to 2000-01, and 8.5 per cent thereafter. Annual growth rate envisaged for the industrial sector in the Eleventh Plan is $10 \%$, and for manufacturing $12 \%$. The private sector, including farming, micro, small and medium enterprises (MSMEs), and the corporate sector, has a significant role to play in achieving the goal of faster and more inclusive growth. MSME sector's role is significant in terms of balanced regional development, and generation of off-farm employment in a dispersed manner.

The MSME sector contributes $8.7 \%$ of the country's Gross Domestic Product (GDP), $45 \%$ of the manufactured output, and $40 \%$ of the country's merchandise exports. MSMEs provide employment to about 60 million persons through 26 million enterprises, as revealed by the Fourth All India Census on MSMEs covering registered and unregistered segments for the reference year 2006-07. As per the quick results of the Census released by Development Commissioner (MSME), registered MSMEs account for 1.56 million (6\%), and unregistered 24.55 million (94\%), totalling 26.11 million enterprises, as against the earlier projected figure of 13 million enterprises for 2006-07 based on the Third Census of Small Scale Industries (Union Ministry of MSME, Annual Report 2011-12).

For the first time, the present Survey includes service enterprises, apart from manufacturing and medium enterprises. The Survey covers MSMEs, Khadi and Village Industries, and Coir Enterprises, as these groups fall administratively under the Union Ministry of MSME. In these categories, registered enterprises have been covered on Census basis, and unregistered enterprises on Sample basis. Unregistered enterprises are generally much smaller in size compared to registered enterprises; these are also referred to as informal sector enterprises; and nearly three-fourths of them are in the service sector. Out of 26.11 million total MSMEs in 2006-07, manufacturing accounts for $28.6 \%$, and the remaining $71.4 \%$ are service enterprises. In the registered enterprises category, the corresponding percentages are 67.1 and 32.9; and in the unregistered enterprises, manufacturing accounts for $26 \%$, and services for $74 \%$. Manufacturing enterprises are 7.47 million [1.05 million registered (14\%), and 6.42 million unregistered (86\%)], and service enterprises are 18.65 million [0.52 million registered $(2.8 \%)$, and 18.13 million unregistered $(97.2 \%)$ ]. Out of 1.05 million registered manufacturing enterprises, $94.2 \%$ are micro, $5.6 \%$ small, and $0.3 \%$ medium enterprises. Among 0.52 million registered service enterprises, $96.9 \%$ are micro, $3.1 \%$ small, and $0.1 \%$ medium enterprises. In respect of employment, unregistered units account for 50.3 million (84.4\%) compared to 9.3 million for registered units (15.6\%). Registered units, thus, account for nearly $6 \%$ of enterprises, and $15.6 \%$ of employment in the MSME sector. Out of 1.56 million MSMEs registered, $94.9 \%$ are micro enterprises (1.48 million), followed by $4.9 \%$ small enterprises $(76,000)$, and $0.2 \%$ medium enterprises $(3,230)$ as per the current definition. The corresponding percentage share of employment of the three segments out of the total registered enterprises employment is 70.2, 25.2, and 4.6, respectively. Women promoted enterprises are 1.92 million -0.22 million registered, and 1.70 million unregistered (13.8\% of registered MSMEs, 7\% of unregistered MSMEs, and 7.4\% of all MSMEs).

In 2006-07, production of MSMEs is estimated at Rs.7,094 billion at current prices, fixed investment Rs.5,008 billion, employment 59.5 million, and exports Rs.1,825 billion at current prices (US \$40.36 billion). In relation to all India export figure of US $\$ 126.4$ billion for 2006- at current prices 07, MSME sector's contribution is $32 \%$, and has grown at $18.9 \%$ over the previous year, compared to $22.6 \%$ for overall exports. The estimates for 2010-11 are 31.15 million total MSMEs, Rs.7,735 billion fixed investment, Rs.10,958 billion production at current prices, and 73.22 million employment. Data relating to MSME exports is available only up to 2007-08. During 2007-08, MSME exports accounted for Rs.2,020.2 billion at current prices (US \$50.25 billion), which works out to $30.8 \%$ of the country's total exports of US $\$ 163.13$ billion; and has grown at $24.5 \%$ over the previous year compared to $29 \%$ for overall exports. From 2006-07, data relating to the newly registered medium enterprises are included in the revised estimates. For earlier years, data cover only micro and small enterprises (Union Ministry of MSME, Annual Report 2011-12).

In the Annual Report 2012-13 of the Union Ministry of MSME (2013), results of the Economic Census 2005 in certain product groups, particularly unregistered service enterprises, not included in the fourth Census of MSMEs have been added to the MSME data available for the unregistered sector from MSME Census. The combined figures for MSME sector, including activities selected from the EC 2005 are presented in Tables 3\&4. As mentioned in these tables, total MSME sector for the reference year 2006-07 works out to 36.18 million enterprises, with employment potential of 80.52 million, fixed investment as Rs.8,685 billion, and production at current prices as Rs.13,514 billion. Projections have been made for the years 2007-08 up to 201112 by the Office of Development Commissioner (MSME) as shown in Table 3. The estimates for 2011-12 reveal that there are 44.77 million total MSMEs, with fixed investment of Rs.11,769 billion, production at current prices Rs.18,343 billion, and employment 101.26 million. 
Total merchandise exports for the country (Table 5) have moved up from US \$52.72 billion in 2002-03 ( $20.3 \%$ growth over the previous year) to $\$ 63.84$ billion in 2003-04 (21.1\% growth), $\$ 83.54$ billion, $\$ 103.09$ billion, and $\$ 126.41$ billion, and \$163.13 billion during 2004-05, 2005-06, 2006-07, and 2007-08, respectively. The growth rate from 2002-03 has been over 20 per cent, except in the recent three years of 2008-09, 2009-10, and 2012-13. For the first time, the export figure crossed \$100 billion in 2005-06, and the trend continued thereafter. In view of the global economic and financial crisis, exports recorded very slow growth of 13.6 per cent in 2008-09, and touched $\$ 185.3$ billion, and negative growth rate of 3.5\% in 2009-10, and touched US \$ 178.75 billion. The deceleration started from September 2008, and negative growth was recorded from October 2008 up to September 2009 (12 consecutive months). During 2000-01 to 2005-06, total exports recorded 18.3 per cent growth rate per annum; performance of MSE sector was 17.3 per cent; and it was as low as 7.0 per cent each for both categories during 1995-96 to 2000-01. Compound annual growth rate of total exports during 200304 to $2006-07$ has been 25.5 per cent.

The performance of total merchandise exports of the country was $\$ 163.13$ billion in 2007-08 (29\% growth over the previous year), $\$ 185.30$ billionin 2008-09 (13.6\% growth), and $\$ 178.75$ billion (decline by $3.5 \%$ ). Compound annual growth rate registered between fiscal years 2004 and 2008 is about $25 \%$. In view of this, annual growth rate of $25 \%$ is envisaged for the next few years. India's share in global trade covering exports and imports is targeted to increase from $1.5 \%$ in 2007 to $5 \%$ by 2020 . The long term policy objective is to double India's share in global trade by 2020. Exports during 2010-11 reached $\$ 251.14$ billion (40.5\% growth over 2009-10), and during 2011-12, \$305.96 billion (21.8\% growth over the previous year). The year 2012-13 has shown deceleration by 1.8 per cent with the export figure as $\$ 300.57$ billion. The vision paper released by Department of Commerce in March 2011 has set the target of $\$ 500$ billion to be reached in the next three years, by 2013-14, i.e., doubling of exports in a period of three years, at an annual growth rate of 26.7 per cent.

Exports from the MSE sector during the post-liberalisation period has been quite impressive, though it had recorded ups and downs in the same direction as total exports over the years. A few years have recorded good performance; many others have witnessed low performance; even negative growth rate in certain years. From 2002-03, the performance has been quite encouraging.

Among the strategies being pursued vigorously in the recent years is the cluster approach for technology upgradation / modernisation, and export promotion. Clusters of small firms located in the adjoining areas, their use of flexible manufacturing system, inter-firm cooperation, and provision of services enable them to derive benefits of collective agglomeration and external economies. Through this effort, the enterprises as a group are able to grow rapidly, upgrade their skills, improve productivity and technology, develop market niche, and gain access to bigger and more distant markets. Experience of cluster programme implementation, however, varies widely from one region to another.

Based on the recommendations of the Abid Hussain Committee Report (1997), and S.P.Gupta Committee Report (2002), the Government of India has announced a number of measures for enhancing the competitive strength of small and medium enterprises to enable them to become globally competitive. In February 2007, a package for promotion of micro and small enterprises has been announced by the Government of India covering legislative measures, credit, fiscal measures, support for cluster-based development, support for technological and quality upgradation, entrepreneurship development, and strengthening the database of the MSE sector.

V. Credit Flow to Micro and Small Enterprises

Table 6(a): Credit Flow to Micro and Small Enterprises (MSEs) from

Scheduled Commercial Banks (SCBs) (2004-12)

Balance outstanding amount in Rs. billion, and per cent as share of Net Bank Credit. From 2008, per cent refers to percentage of Adjusted Net Bank Credit (ANBC) or credit equivalent of off balance sheet exposure (OBSE), whichever is higher.

\begin{tabular}{|c|c|c|c|c|c|c|c|c|}
\hline \multirow[t]{2}{*}{$\begin{array}{c}\text { Year end- } \\
\text { March / period }\end{array}$} & \multicolumn{2}{|c|}{$\begin{array}{c}\text { Public Sector Banks } \\
\text { (PSBs) }\end{array}$} & \multicolumn{2}{|c|}{ Private Sector Banks } & \multicolumn{2}{|c|}{ Foreign Banks } & \multicolumn{2}{|c|}{ Total SCBs } \\
\hline & Amount & $\%$ & Amount & $\%$ & Amount & $\%$ & Amount & $\%$ \\
\hline $\mathbf{1}$ & 2 & 3 & 4 & 5 & 6 & 7 & 8 & 9 \\
\hline 2004 & $583.11(10.8)$ & 10.3 & $75.90(10.7)$ & 7.3 & $53.07(39.3)$ & 10.1 & $712.08(11.9)$ & 9.9 \\
\hline 2005 & $680.00(16.6)$ & 9.5 & $85.92(13.2)$ & 5.4 & $69.07(30.1)$ & 10.2 & $834.99(17.0)$ & 8.9 \\
\hline 2006 & $824.34(21.2)$ & 8.1 & $104.21(21.3)$ & 4.2 & $84.30(22.1)$ & 9.5 & $1012.85(21.7)$ & 7.5 \\
\hline 2007 & $1025.50(24.4)$ & 7.8 & $131.36(26.1)$ & 3.9 & $116.37(38.0)$ & 10.3 & $1273.23(25.7)$ & 7.2 \\
\hline 2008 & $1511.37(47.4)$ & 11.1 & $469.12(257.1)$ & 13.7 & $154.89(33.1)$ & 12.2 & $2135.38(67.7)$ & 11.7 \\
\hline 2009 & $1914.08(26.6)$ & 11.3 & $466.56(-0.6)$ & 11.8 & $180.63(16.6)$ & 11.2 & $2561.27(19.9)$ & 11.4 \\
\hline 2010 & $2763.19(44.4)$ & 13.3 & $648.25(38.9)$ & 13.8 & $211.47(17.1)$ & 12.7 & $3622.91(41.4)$ & 13.4 \\
\hline 2011 & $3766.25(36.3)$ & 15.1 & $878.57(35.5)$ & 16.4 & $215.01(1.7)$ & 12.9 & $4859.83(34.1)$ & 15.2 \\
\hline 2012 & $3966.00(5.3)$ & 13.1 & $1105.00(25.8)$ & 15.2 & $217.00(0.9)$ & 11.0 & $5288.00(8.8)$ & 13.3 \\
\hline
\end{tabular}

www.iosrjournals.org 
Small and Medium Enterprises and Inclusive Growth in the Globalisation Era

Table 6(b): CAGR (Compound annual growth rate) of Credit Flow to MSEs from SCBs (2001-11)

\begin{tabular}{|l|l|l|l|l|l|l|l|l|}
\hline $\mathbf{1}$ & $\mathbf{2}$ & & $\mathbf{4}$ & $\mathbf{6}$ & $\mathbf{8}$ & $\mathbf{8}$ \\
\hline $2001-05$ & 8.9 & & 1.5 & & 17.3 & & 8.6 & \\
\hline $2005-08$ & 30.5 & & 76.1 & & 30.9 & & 36.8 & \\
\hline $2005-09$ & 29.5 & & 52.7 & & 27.2 & & 32.3 & \\
\hline $2008-11$ & 35.6 & & 23.3 & & 11.6 & & 31.5 & \\
\hline $2009-11$ & 40.3 & & 37.2 & & 9.1 & & 37.7 & \\
\hline
\end{tabular}

Notes: 1. Figures in parentheses indicate percentage variation over the previous year.

2. Compound annual growth rate (CAGR) has been worked out for specified periods.

Source: Reserve Bank of India (2012), Report on Trend and Progress of Banking in India 2011-

12, and of earlier years from 2004-05, Mumbai. Available at www.rbi.org.in

Affordable and timely availability of finance to the MSME sector is of critical importance to its development. Flow of credit to micro and small enterprises (MSEs) as percentage of net bank credit of public sector banks, private sector banks, and foreign banks declined steadily from 2002. This decline can be attributed to a number of factors. One of them, and perhaps the most important of them, is the perceived higher risk for MSEs, and high transaction cost for the large number of transactions. It is believed that economies of scale and absence of transparency are not allowing the MSEs to have access to bank loans. Small and medium enterprises need special treatment in the context of global competitive environment. Special instruments/ products of credit need to be devised for enhancing their competitiveness.

In pursuance of the recommendations of the Internal Group on Credit Flow to the SME sector (Chairman: C. S. Murthy), a policy package for stepping up credit to SMEs was announced by the Hon'ble Union Finance Minister on August 10, 2005 in the Parliament for enhancement of flow of credit to the SME sector. In order to double the flow of credit to the SME sector from Public Sector Banks (PSBs) in a period of five years from 2004-05 to 2009-10, they were advised to fix their own targets for funding SMEs, in order to achieve 20 per cent, year on year, growth in credit to SMEs. Banks were advised to follow transparent rating system with cost of credit being linked to the credit rating of the enterprise. It is heartening to notice that the target set by the Union Finance Ministry for doubling credit flow to the SME sector within five years, has been achieved within a three - year period (2005-08). As presented in Table 6(a), credit from PSBs increased from Rs.680 billion at end-March 2005 to Rs.1,511 billion by 2007-08. As per cent of net bank credit, the improvement is from 9.5 to 11.1. Annual growth rate of credit in 2007-08, in particular, has been quite significant. The same pattern holds good for private sector banks and foreign banks as well, where the credit increased from Rs.86 billion to Rs.469 billion, and from Rs.69 billion to Rs.155 billion, respectively. Improvement in the case of all scheduled commercial banks is from Rs.835 billion in end-March 2005 to Rs.2,135 billion in end-March 2008. CAGR recorded during 2005-08 is 30.5\% for PSBs, 76.1\% for private sector banks, and 30.9\% for foreign banks, and 36.8\% for all SCBs. Out of the credit flow to the MSE sector from SCBs at the end of March 2008, the shares of PSBs, private sector banks, and foreign banks are 70.8\%, $22.0 \%, 7.2 \%$, respectively. The tempo of turn around recorded during this period needs to be sustained and further improved in the ensuing years. Performance during 2008-09 has been much below expectations because of the global financial crisis; and during 2009-10, recovery trend has been noticed, and during 2010-11 there has been decline in growth rates. CAGRs presented in Table 6(b) reveal that growth rate for PSBs has been much better during 2008-11 compared to the other categories, and also compared to its 2005-08 picture. During 201112 , decline in growth rate has been noticed in respect of all categories, with the share of adjusted net bank credit declining to $13.1 \%$ for PSBs, and $13.3 \%$ for all SCBs.

Credit Guarantee Scheme: Credit Guarantee Fund Scheme for MSEs is implemented by the Government through Credit Guarantee Fund Trust for Micro and Small Enterprises (MSEs), with the objective of facilitating credit flow to MSEs, particularly to micro enterprises by providing guarantee cover for loans up to Rs.100 lakh, without collateral/ third party guarantees. For making the scheme more attractive to both lenders as well as borrowers, several modifications have been made, which, inter alia, include: (a) enhancement in the loan limit to Rs.100 lakh, (b) enhancement of guarantee cover from $75 \%$ to $85 \%$ for loans up to Rs.5 lakh, (c) enhancement of guarantee cover from $75 \%$ to $80 \%$ for micro and small enterprises owned/operated by women and for loans in the North Eastern Region, (d) reduction in one-time guarantee fee from $1.5 \%$ to $1 \%$, and annual service charge from $0.75 \%$ to $0.5 \%$ for loans up to Rs.5 lakh, and (e) reduction in one-time guarantee fee for North Eastern Region from $1.5 \%$ to $0.75 \%$.

During 2009-10, a Working Group has been constituted by RBI to review the working of the scheme in order to enhance the usage, and facilitate increased flow of collateral-free loans to MSEs. The other terms of reference of the Group include to make suggestions for simplifying the existing procedures and requirements for obtaining cover, and invoking claims under CGTMSE, and to examine the feasibility of a whole turnover guarantee for MSE portfolio. The MSME (Risk Capital) Fund of Rs.1,000 crore with the Small Industries 
Development Bank of India (SIDBI) announced in the Union Budget 2008-09, which has become operational, will facilitate the flow of enhanced equity support and venture capital to MSMEs. Another Fund created in SIDBI in 2008 is the MSME (Refinance) Fund of Rs.1,600 crore for enhancing refinance facility for MSMEs. This has been enhanced by Rs.2,000 crore later. Another fund created in SIDBI in 2009 is a special fund of Rs.4,000 crore to incentivise banks and state financial corporations to lend to MSEs by refinancing 50 per cent of lending to MSEs. Another measure adopted by RBI was making available refinance amount of Rs.7,000 crore to SIDBI on December 6, 2008 to enhance credit delivery to the MSME sector. During 2010-11, Rs.4,000 crore and during 2011-12, Rs.5,000 crore has been provided to SIDBI for refinancing incremental lending by banks. In 2012-13, India Opportunities Venture Fund has been created in SIDBI with a corpus of Rs. 5,000 crore to enhance the availability of equity, and enable MSMEs get greater access to finance (Announcement in the Union Budget 2012-13).

Credit Linked Capital Subsidy Scheme (CLCSS) for MSEs: The scheme aims at facilitating technology upgradation of MSEs by providing 15\% capital subsidy (limited to a maximum of Rs.15 lakh) for purchase of plant and machinery. Maximum loan eligible for calculation of subsidy under the scheme is Rs.100 lakh. The admissible capital subsidy is calculated with reference to the purchase price of plant and machinery. 48 well established and improved technologies/sub-sectors have been approved under the scheme. The scheme is implemented through 11 nodal banks/agencies including SIDBI, NABARD, and NSIC.

The National Commission for Enterprises in the Unorganised Sector (NCEUS) (Chairman: Arjun K. Sengupta), under the Union Ministry of MSME submitted two reports to the Prime Minister in November 2007. They are: (i) Financing of Enterprises in the Unorganised Sector, and (ii) Creation of a National Fund for the Unorganised Sector (NAFUS). The recommendation on the creation of the fund flows from the first report. The first report deals with financing of the enterprises in the non-farm unorganised sector. It examines in depth the status of financing of the sector, and deals with deficiencies in institutional infrastructure, and constraints in financing this sector. The report while giving the recommendation on financing, also suggested the creation of NAFUS. The second report deals with the recommendation on the creation of NAFUS. It presents the rationale, organisation model, functions, and sources of financing of the Fund. The mandate for the creation of the Fund is derived from the National Common Minimum Programme of the UPA Government. The final report brought out as a publication and submitted by NCEUS to the Prime Minister in April 2009 is titled, The Challenge of Employment in India - An Informal Economy Perspective (2009). The Government has taken significant steps arising out of the recommendations of the Commission's earlier reports. It is hoped that further steps will be taken to ensure decent employment conditions and social security to 93 per cent of work force so that these will enhance the goal of inclusive development resulting in a life of dignity and security to the working poor of our country. ${ }^{4}$

The Committee's report reveals that the unorganised sector constitutes 93 per cent of all small enterprises estimated at 58 million in 2007 with a total employment of 104 million. The National Fund is envisaged as a statutory body funded by the Central Government and financial institutions that will primarily focus on non-farm micro enterprises with investment in plant and machinery of less than Rs.5 lakh. The Fund will be created on the pattern of funds operated by NABARD, and exclusively meant for meeting the financing and promotional assistance gaps in the development of the non-farm unorganised sector. Being a statutory body, it would leverage funds from the market, and national and international institutions to realise its objectives. The proposals given in the two reports are under the consideration of the Ministry of MSME.

The Eleventh Five Year Plan proposes the targeted livelihood support programmes aimed at increasing productivity and incomes of the poor in several low income occupations, such as micro and small enterprises, weavers, artisans, craftsmen, etc. However, the lack of concern at the state and lower implementation levels for the plight of the unorganised sections renders many of these programmes infructuous. In this context, the recommendations on social security made by the NCEUS assume significance. The UPA Government has introduced schemes to provide social security coverage through life cover, health insurance, and extension of old age pension on the lines recommended by NCEUS but by restricting the coverage to sections of below the poverty line (BPL) households.

Scheme of Fund for Regeneration of Traditional Industries (SFURTI) was announced in the Union Budget 2004-05, and has become operational, with an initial allocation of Rs.100 crore in the Ministry of MSME to cater to the needs of khadi and village industries, and coir industries. The development of around 100 clusters under the scheme in khadi, village and coir sectors, with a total cost of Rs.97.25 crore over a period of

4 Government of India, National Commission for Enterprises in the Unorganised Sector (NCEUS)(Chairman: Arjun K. Sengupta) (2009), The Challenge of Employment in India - An Informal Economy Perspective, Report of the NCEUS in two volumes (Vol. 1 -Main Report, and Vol. 2 - Annexures), Academic Foundation, New Delhi. 
five years beginning from 2005-06 up to 2009-10, will make these industries more productive and competitive, and increase employment opportunities in rural and semi-urban areas in the country. The scheme covers an estimated 50,000 families. The objective of the scheme is to establish a regenerated, holistic, sustainable, and replicable model of integrated cluster-based development of traditional industries in KVI and coir sectors. SFURTI is a Central scheme, being implemented without any financial contribution by the States / Union Territories. SFURTI is the first organised and systematic attempt at introducing cluster-based development approach in the KVI and Coir sectors covering rural and traditional industries. ${ }^{5}$.

\section{De-reservation of Products for Manufacture in Micro and Small Enterprise Sector, and Facilitating greater Equity Participation including FDI}

The policy of reservation of products for exclusive manufacture in micro and small enterprise (MSE) (earlier SSI) sector was started in 1967. The objective of reservation was to protect the interests of the SSI sector. However, with the gradual opening up of the economy, and policy of reservation, there has been progressive de-reservation of a number of items reserved for exclusive manufacture by the MSE sector. The objective of progressive de-reservation was to provide for opportunities for technological upgradation, promotion of exports, and economies of scale, in order to encourage modernisation, and enhance the competitiveness of MSEs in view of the liberalisation and globalisation of the economy. After due consultation with the stakeholders, the Advisory Committee of the Ministry of MSME de-reserved a number of items from the reserved list. The recent ones are 125 items in March 2007, 79 in February 2008, and 14 in October 2008. The total number of items continuing in the reserved list by March 2009 stands at 21. In September 2009, the remaining 21 items were also notified as de-reserved, with the condition that medium and large units entering these items with or without foreign direct investment (FDI) should commit for exporting $50 \%$ of their production within a maximum period of three years. They should obtain an industrial licence. If the FDI is more than 24\%, big players had to obtain prior approval of Foreign Investment Promotion Board. The 2009 September press release removed this process of obtaining permission if the FDI in equity is above $24 \%$, and permitted FDI or participation by other businesses in MSMEs without a ceiling. This enabled MSMEs to attract FDI or investment from other companies to a greater extent. Other developments which enabled MSMEs to attract FDI or investment from other companies to a greater equity is passing of two acts, Limited Liability Partnership Act, and single person promoted companies under the Companies Act. De-reservation has, thus, led to availing the benefits of economies of scale by bigger units by using advanced technologies.

\section{Cluster Development Approach ${ }^{6}$}

For over a decade, the cluster approach is being implemented as a potent tool for achieving the overall development of clusters or groups of SMEs, covering artisan and micro enterprises as well. Various ministries and departments of the Centre are adopting the cluster approach as a pivotal strategy for enhancing productivity and competitiveness as well as capacity building of SMEs in the country. The primary characteristic of the cluster-based approach consists in nurturing the value-chain through a range of carefully crafted demand-side and supply-side policy interventions. Key benefits of a cluster-based approach to developing the SMEs are as follows: (a) Networking among enterprises, (b) Strengthening of the human capital, (c) Technology and skill upgradation, (d) Lowered costs, (e) Improved bargaining power, (f) Global visibility, (g) Easier access to finance, (h) Greater government support, and (i) External players within the value chain.

Under the scheme of cluster development, the benefit of a whole variety of interventions, ranging from exposure to skill development, from credit to marketing, and from technological improvements to better designs and products is given to concentrations of enterprises in a contiguous belt. With the government funding and participation of cluster actors, developmental interventions are carried out for a period of 3-5 years to enhance the competitiveness and collective efficiency of the clusters, and to integrate them with the global economy, and global supply chain in addition to addressing the need for enhancing domestic marketing.

The Micro and Small Enterprises Cluster Development Programme (MSE-CDP) was reviewed in 2006-07 to accelerate holistic development of clusters, including provision of common facility centres, developed sites for new enterprises, upgradation of the existing industrial infrastructure, and provision of exhibition grounds / halls, and also for the creation and management of infrastructure-related assets in publicprivate partnership mode. The ceiling on project outlay for infrastructure development has been raised to Rs. 10 crore per cluster. From October 2007, the scope of the scheme has been enlarged to include provisions for development / upgradation of physical infrastructure also. Modifications made to the scheme are as follows: (a) The scheme of 'Integrated Infrastructure Development Centres' has been subsumed under the cluster

${ }^{5}$ Union Ministry of MSME (2013), Annual Report 2012-13, New Delhi.

${ }^{6}$ Development Commissioner (MSME) (2010), Guidelines under Micro and Small Enterprises -Cluster Development Programme (MSE-CDP), Laghu Udyog Samachar (LUS), November, pp.3-22. 
development programme, with all its existing features and funding pattern. Assistance under the scheme will also be available for the following purposes: (b) for setting up new clusters / industrial estates, and for improving infrastructure in the existing industrial estates; (c) for clusters developed exclusively for MSEs operated, and / or owned by women; and (d) to associations of women entrepreneurs for establishing exhibition centres at central places for display and sale of products of women-owned MSEs. The guidelines of the MSECDP were revised in February 2010 with enhanced funding and simplification of procedures. In the recent years, the cluster approach has been made an integral part of most of the schemes being implemented by the Ministry of MSME, covering all components of the National Manufacturing Competitiveness Programme (NMCP). Other Union ministries such as Textiles, Food Processing Industries, etc. have also implemented the cluster approach in respect of the product lines covered by them. Provisions under different phases of MSE-CDP of the Ministry of MSME are briefly recalled here.

Under MSE-CDP, financial assistance is provided as grant-in-aid by the Government of India (GoI), Ministry of MSME, and administered by the Office of Development Commissioner (MSME), and its field offices for five identified phases of the cluster development programme.

1. For preparing a Diagnostic Study Report (DSR) for a cluster of MSEs, GoI grant per cluster is a maximum of Rs.2.5 lakh;

2. For soft interventions like awareness generation, capacity building, exposure visits, technology upgradation, market development, brand equity, trust building, business development, etc., GoI grant is $75 \%$ of the sanctioned amount of the maximum project cost of Rs.25 lakh per cluster [90\% for North Eastern \& Hill States, and clusters with more than 50\% (a) micro/village, (b) women owned, and (c) SC/ST enterprises];

3. For the preparation of a Detailed Project Report (DPR), GoI grant is up to Rs.5 lakh per cluster;

4. For hard interventions such as setting up of a Common Facility Centre (CFC), GoI grant is $70 \%$ of the cost of the project, i.e., a maximum of Rs. 15 crore [90\% for NE \& Hill states, and clusters with more than 50\% (a) micro/village, (b) women owned, \& (c) SC/ST enterprises]. Hard interventions include creation of tangible assets like testing facility, design centre, production centre, effluent treatment plant, training centre, R\&D centre, raw material bank / sales depot, product display centre, information centre, and any other need based facility; and

5. For infrastructure development in a cluster, GoI grant is $60 \%$ of the cost of the project, i.e., a maximum of Rs. 10 crore, excluding the cost of land [ $80 \%$ for NE \& Hill States, and industrial estates / areas with more than $50 \%$ (a) micro, (b) women owned, \& (c) SC/ST enterprises]. For existing clusters, upgradation proposals will be based on the actual requirement. The state / UT governments will provide suitable land for the projects. In the estimated cost to set up an infrastructure development project (excluding cost of land), GoI provides grant-inaid. The remaining amount may be obtained as loan from SIDBI/ banks / financial institutions or equity from state / UT government. The state / UT government will meet the cost in excess of Rs.10 crore or any escalation in cost. Office of the Development Commissioner (MSME) with the approval of the Steering Committee, may appoint Competent Programme Management Service Providers (PMSPs) for facilitating formation of various proposals and their implementation.

In the present scenario of knowledge-based economy, formation of consortia, self help groups, dynamic associations may yield benefits for pursuing issue-based strategic interventions in industrial clusters. A critical mass of MSEs can join hands under the umbrella of a formal entity called cluster led by a group of beneficiaries (Special Purpose Vehicle-SPV). Confidence building and trust building are the two main pillars of building up cluster development initiatives. Guidelines under MSE-CDP have been published in Laghu Udyog Samachar (LUS), November 2010, pp. 3-22.

Two institutions have been developed as national resource centres for cluster development by the Ministry of MSME. These are: (i) National Institute for Micro, Small and Medium Enterprises (NI-MSME), Hyderabad, and (ii) International Centre for Cluster Competitiveness and Growth at the Entrepreneurship Development Institute of India (EDI), Gandhinagar. These institutions impart training to cluster development executives, monitor cluster development work, and assist in the formulation of policies and programmes for cluster development and guidance. SIDBI has been focusing on greater and easier flow of credit through its branches located in clusters while extending developmental support. These branches are now named as Small Enterprise Financial Centres. They take up co-financing with bank branches through a strategic alliance with banks. Commercial banks have been advised to adopt a full-service approach to cater to the diverse needs of the SME sector through banking services to cluster enterprises by adopting a four $-\mathrm{C}$ approach, namely, customer focus, cost control, cross sell, and contain risk. A few clusters are planned to be developed as knowledge hubs, and 25-30 clusters as 'model clusters' with technical assistance from DFID (Department for International Development of the United Kingdom). The Government has identified six centres to be developed as mega clusters. These are two each in handlooms, powerlooms, and handicrafts. The enterprises located in these clusters will scale up production both in quantity and quality to meet the needs of the domestic and global markets. 


\section{Dimensions of Manufacturing Competitiveness}

The MSE-CDP was the major initiative geared to enhancement of collective efficiency of firms and for promoting collaborative efforts among firms located in the vicinity. The rationale is that the thinning of promotional initiatives among a large number of individual firms would imply a significant erosion of the intended benefits. A decade of experimentation in the collective efficiency models indicates this. While these models have contributed to enhancement of overall productivity of firms under clusters, manufacturing capabilities of the country have suffered. It was in this context that the National Manufacturing Competitiveness Programme (NMCP) was launched in 2005. The NMCP mainly deals with firm level competitiveness. The broad elements of manufacturing competitiveness policy are: (a) Technology and innovation enhancement, (b) Protection of intellectual property rights (IPRs), and (c) Entrepreneurship policy.

The National Manufacturing Competitiveness Council (NMCC) was set up in 2004, as an interdisciplinary and autonomous body to energise and sustain the growth of the manufacturing industry. Broadly, the objectives of the Council are: identification of manufacturing sectors having globally competitive potential, as also their problems and constraints with respect to structure and size, technology gaps, modernisation needs, etc., and evolving sector-specific strategies for enhancing the competitiveness of manufacturing sectors. Its functions would, inter alia include: sectoral and enterprise level initiatives, innovation and technology development $(R \& D)$, entrepreneurship promotion, infrastructure and enabling facilities, trade and fiscal policies, and employment generation. The NMCC has helped a number of enterprises in sunrise sectors such as food processing, textiles and garments, pharmaceuticals, leather, and information technology (IT) in increasing their capabilities for global competitiveness, minimising technological gaps, providing infrastructure and enabling facilities, and supporting with trade and fiscal policies.

Globalisation of businesses has increasingly drawn SMEs into global value chains through different types of activities. The networking of globalisation has been developed in recent years through joint efforts in selling, buying, technological development, quality standards, learning networks, and market research. Many SMEs are trained to establish collaborative linkages with global suppliers in which the role of the government is important in promoting the network. The MSMEs Development Act, 2006 has been designed to solve the constraints and problems faced by SMEs, and enable the enterprises to avail of greater market opportunities arising from globalisation in the World Trade Organisation (WTO) administered foreign trade.

The NMCP that started in 2005 covers 10 components of the SME sector. The coverage and main aspects of these components are explained here. Guidelines for implementing each of the components of NMCP are periodically published in Laghu Udyog Samachar (LUS) by Development Commissioner (MSME). The relevant issues of LUS in which guidelines for each of the schemes have been published are indicated at appropriate places in the subsequent paragraphs. Some of them have also been released as booklets. Website www.dcmsme.gov.in/schemes of Development Commissioner (MSME) furnishes provisions of various schemes of the Ministry of MSME.

\subsection{Marketing Support and Assistance to MSMEs through Bar Coding (Bar Coding)}

Bar code is a series of parallel vertical lines (bars and spaces), that can be read by Bar Code scanners. It is used worldwide on the product packages, as price tags, carton labels, and even on credit card bills. When it is read by scanners, the restored information on product profile and its other attributes is made available to the consumer, and this facilitates better marketing of products. The Bar Coding is a unique, universal, and international concept which can be recognised anywhere in the world. Bar Coding is essential in many ways, inter alia, to eliminate delays and inaccuracies inherent in manual checking / identification of each category of goods indicating price and other essential details, maintaining simultaneous inventory entries, management and control, ordering timely replacements, rapid issuing printed memos, and receipts after accounting, etc. Bar Coding has become a pre-requisite for all suppliers and buyers in today's digitalised market, and Indian MSEs will have opportunities to grow by adopting it. Bar Coding enables higher price realisation at the exporter's end, instead of at the buyer's end; and helps promote Indian value added products globally. Using international digitalised numbering standards represents a small but significant step in accessing global and ever growing domestic markets (LUS, February 2010, pp. 12-13).

Bar Coding is an important marketing tool having wide global acceptability. In order to encourage units in the sector to adopt bar coding, a provision for reimbursement of $75 \%$ of one-time registration fee from January 2002, and annual fees for the first three years from June 2007 paid to Global Standard One (GS1) India (formerly EAN India) (an autonomous body under the Ministry of Commerce and Industry) by MSEs for adoption of Bar Coding has been made under SSI-MDA (Market Development Assistance) Scheme. Besides, there is a provision for organising a one-day sensitisation awareness programmes, and preparation of publicity material for MSEs and other stake-holders concerned.

\subsection{Support for Entrepreneurial and Managerial Development of MSMEs}




\section{through Incubators (Business Incubator)}

The concept of business incubation is relatively new for MSMEs. The Incubator scheme makes available a new window for supporting and nurturing business based on new ideas. The idea is to promote development of knowledge-based technological innovative ventures, and to improve the competitiveness and survival strategies of MSMEs. Incubation of ideas under the guidance of an incubator will facilitate sustainable development. Under the scheme, knowledge institutions like engineering colleges, research laboratories, and university science and technology departments are provided financial assistance up to Rs.6.25 lakh for incubating each of the new ideas. The incubator institution provides technology guidance, workshop and laboratory support, and linkages with other agencies for the successful launching of the business, and guides the entrepreneurs in running the business for about 3 years. During the 11th Plan period up to March 2012, provision of Rs.135 crore has been made by GoI for incubating 2000 ideas (LUS, January 2011, pp. 23-27).

Under the scheme, 100 'Business Incubators (BIs)' are to be set up under technology (host) institutions over a 4-year period at 25 per year; and each BI is expected to help the incubation of about 10 new ideas or units. For this service, which includes the provision of laboratory / workshop facilities and other assistance / guidance to young innovators, each BI will be given between Rs.4-8 lakh per idea / enterprise nurtured by them, limited to a total of Rs.62.5 lakh for 10 units. In addition, Rs.4 lakh will be provided for the upgradation of infrastructure, orientation / training, and administrative expenses, resulting in a total of Rs.66.5 lakh for promoting 10 enterprises.

\subsection{Setting up of Mini Tool Room and Training Centres (Mini Tool Room)}

Mini Tool Room and Training Centres will be promoted on Public-Private Partnership (PPP) Model for providing technological support to MSMEs by creating capacities in the private sector, for designing and manufacturing quality tools, and for providing training facilities in related areas. Total project cost for the scheme for the 11th Plan period is Rs. 210 crore including GoI's contribution of Rs. 135 crore. Implementation is planned in three ways: (a) Private Partner (Centre PPP Model); (b) SPV set up by the states in partnership with private partners (State PPP Model); and (c) State or state agency other than NGOs (Centre-State Model). The objectives of Mini Tool Rooms are as follows (LUS, December 2010, pp. 9-16).

to improve the competitiveness of the MSMEs engaged in manufacturing activity by creating capacities in the private sector for designing and manufacturing quality tools;

$>\quad$ to bridge the gap between demand and supply of trained manpower in the industry; \&

$>\quad$ to encourage Research and Development, and optimisation of cost and quality of delivery, leading to enhanced competitiveness of the manufacturing sector.

In Model I (Centre PPP Model), the project is to be set up and operated by a private partner. Financial assistance will be given by GoI to meet the viability gap on a case-to-case basis, and it will be restricted to $40 \%$ of the project cost (not exceeding Rs.9 crore). In Model II (State PPP Model), the project is to be set up by the state government in co-operation with NGOs (SPVs), who will run the project on mutually agreed terms. Financial assistance will be equal to $90 \%$ of the cost of machinery, restricted to Rs. 9 crore. However, in order to retain a say in the management, at least $26 \%$ of the share should be with the state government. This Model can be considered if Model I is not found to be feasible. In Model III (Centre-State Model), project is to be set up and managed by the state government / state government agency. Financial assistance will be equal to $90 \%$ of the cost of machinery, restricted to Rs. 9 crore. Financial assistance equal to $75 \%$ of the cost of machinery, restricted to Rs.7.5 crore can also be sanctioned for upgradation of an existing state tool room. This Model could be resorted to only where both Model I and Model II are not found to be practicable. First preference will be to adopt Model I. Others can be considered in the sequence stated above. Project sponsor's contribution should be at least $15 \%$ of the overall project cost.

\subsection{Building Awareness on Intellectual Property Rights (IPRs)}

The objective is to create and enhance awareness about IPRs among units in the sector so as to enable them to take appropriate measures for protecting their ideas and business strategies, and also avoiding infringement of the intellectual property belonging to others. IP refers to legal rights that result from intellectual activity in the industrial, scientific, literary, and artistic fields to preserve the innovations and R\&D efforts of individuals and companies. It could be in the form of patents, trademarks, geographical indications, industrial designs, layout designs of integrated circuits, plant variety protection, and copyright. Utilisation of IPR tools will enhance the competitiveness of MSMEs through technology upgradation. These initiatives are proposed to be developed through PPP mode to encourage economically sustainable models for the overall development of MSMEs. The scheme provides for financial assistance for taking up the following identified initiatives on a cluster basis: (a) Awareness / sensitisation programmes on IPRs; (b) Pilot studies in selected clusters / groups of industries; (c) Interactive seminars / workshops; (d) Specialised training; (e) Assistance for grant of patent / GI 
registration; (f) Setting up of IP Facilitation Centre; and (g) Interaction with international agencies (LUS, February 2011, pp.11-20).

\subsection{Application of Lean Manufacturing Techniques (LEAN)}

The focus is on helping MSMEs adopt Lean Manufacturing (LM) techniques so as to enhance their productivity, efficiency and competitiveness by reducing or eliminating manufacturing waste, and streamlining the system through application of various LM techniques, e.g., 5S System, Visual Control, Standard Operating Procedures (SOPs), Just in Time (JIT), KANBAN System Cellular Layout, Value Stream Mapping, Poka Yoke or Mistake Proofing, Total Productive Maintenance (TPM), etc. Worker empowerment is also emphasised. Initially the scheme will be implemented in 100 mini clusters (each of a group of 10 enterprises) for one year at a total cost of Rs.30 crore. The scheme is in operation from July 2009. Later it will be extended to 300-500 clusters in a few years. Results will be in the form of improved process flows, reduced engineering time, proper personnel management, better space utilisation, scientific inventory management, etc. These will improve the quality of products and reduce costs. LM counsellors appointed for a few clusters will identify and implement appropriate LM techniques. The effort will bring about improvement in the quality of products at lower costs, which will enhance the competitive ability of enterprises. National Productivity Council, New Delhi has been appointed the National Monitoring and Implementation Unit for the pilot project. The MSME-Development Institute at the state level has nominated the nodal officer for coordination with NPC at the local / field level. Awareness programmes will be conducted in the clusters. Consultant's fee for each cluster up to $80 \%$ will be borne by GoI, and $20 \%$ by the beneficiary enterprises (LUS, November 2009, pp.6-8).

\subsection{Quality Management Standards (QMS) and Quality Technology Tools (QTT)}

This was launched during 2008-09, with a budget provision of Rs.40 crore for 4 years. The scheme aims at improving the quality of products in the MSME sector, and inculcating quality consciousness among units of the sector. The major activities envisaged under the scheme are: (a) Introduction of appropriate modules for technical institutions with a target coverage of 2000 technical institutions; (b) Organising awareness campaigns every year for MSMEs; (c) Organising competition-watch (c-watch) every year in the two sectors; (d) Implementation of QMS and QTT in 100 selected MSEs every year; and (e) Monitoring at least two international study missions per year. The focus is on sensitising and encouraging MSMEs to adopt the latest QMS and QTT techniques so as to strengthen their operations, and to keep a watch on the sectoral developments in the country by undertaking defined activities (LUS, October 2009, pp. 16-19).

\subsection{Energy Efficiency and Quality Certification Support (Energy)}

The focus is on sensitising enterprises and spreading an awareness about the need and benefits of adopting energy efficient technologies and using different quality certification measures for reducing emission of green house gases (GHGs), and improving the quality of products at reduced costs so as to improve the competitiveness of the enterprises in the global arena. The following initiatives are being pursued under this scheme: (a) Conducting awareness programmes on energy efficient technologies, availability of energy efficient equipments, and benefits from energy efficient techniques and clean development mechanism (CDM); (b) Supporting energy audits in sample units in clusters; (c) Promoting replication of model energy efficient technologies (EET) after preparing detailed project reports in the clusters, and implementation of the cluster plan; (d) An innovative concept of cluster-based carbon credit aggregation centres (CCACs) has been planned under the scheme to initiate MSMEs to CDM benefits; and (e) MSMEs are encouraged to acquire product certification / licences from national / international bodies, and adopt other technologies mandated as per global standards (LUS, March 2011, pp. 16-25).

The activity will be implemented through SIDBI which will function as the implementing agency. Both technical and overall project appraisal by SIDBI / other Bank will be taken into consideration prior to the sanction of assistance in the form of grants by the Ministry of MSME. About 390 units will be supported for implementing EETs in MSMEs in potential clusters under this activity. While $25 \%$ of the project cost will be provided as subsidy by GoI, the balance amount is to be funded through loan from SIDBI / other banks /financial institutions. The minimum contribution as required by the funding agency will have to be made by the MSME. Besides reducing energy cost, the activity will also enable the implementing enterprises in obtaining credits, which are tradable in the National and International Commodity Exchanges. Clusters for setting up the Carbon Credit Aggregation Centres (CCACs) for introducing and popularising Clean Development Mechanism (CDM) will be identified on the basis of the CDM implementation potential in the cluster or applications received from the stakeholders. 


\subsection{Marketing Assistance and Technology Upgradation (Modern Marketing Techniques)}

Competitiveness in marketing is sought to be improved through Marketing Assistance and Technology Upgradation Scheme, by using the latest techniques and technologies suitable for specific product groups on a cluster basis. The broad activities under the scheme include technology upgradation in packaging, development of modern marketing techniques, competition studies, state / district exhibition, corporate governance practices, marketing hubs, etc. Under the scheme introduced in 2010, ten product groups have been identified for studies on packaging. Further, 140 units have been identified for participation in industry fairs and exhibitions (LUS, February 2011, pp. 7-10).

\subsection{Promotion of Information and Communication Technology Tools (ICT Tools)}

The scheme envisages that SME clusters, which have quality production and export potential, shall be identified, encouraged and assisted in adopting ICT applications to achieve competitiveness in the national and international markets. The activities planned under the scheme include: identifying target clusters for ICT intervention, setting up of E-readiness infrastructure, developing web portals for clusters, skill development of MSME staff in ICT application, preparation of local software solution for MSMEs, construction of e-catalogue, e-commerce, etc. and networking MSME cluster portal on the national level portals in order to outreach MSMEs into global markets. The scheme launched in 2010 will initially be implemented in 100 clusters (LUS, February 2011, pp. 7-10).

\subsection{To Bring Design Expertise through Design Clinics (Design Clinic)}

The scheme brings design experts on a common platform to enable MSMEs to access expert advice and solutions for their real time design problems, resulting in continuous improvement and value addition to the existing products. It also aims at developing value added cost effective solutions. The scheme introduced in 2010 comprises of two major parts - design awareness, and design project funding. The design awareness stage comprises activities like seminars, workshops, diagnostic studies of clusters. In design project funding, projects of students, consultants / designers, and consulting organisations are assisted by GoI by providing $60 \%$ of the project cost by way of grant. The scheme will initially be implemented in 200 MSME clusters (LUS, February 2011, pp. 7-10).

\section{Central Public Procurement Policy (CPPP) and Defence Production Policy:}

The Union Ministry of MSME has notified a Public Procurement Policy for goods produced and services rendered by micro and small enterprises (MSEs) through its MSEs order, 2012 effective from $1^{\text {st }}$ April 2012. The policy mandates that all central ministries/departments/central public sector undertakings (CPSUs) shall procure a minimum of 20 per cent of their annual value of goods/ services required by them from MSEs. Further, the policy has earmarked -sub-target of 4 per cent procurement out of this 20 per cent from MSEs owned by scheduled caste/scheduled tribe (SC/ST) entrepreneurs. This is to be achieved in a period of three years, beginning from April 2012. By April 2015, the overall procurement goal of a minimum of 20 per cent shall be made mandatory. The annual goal of procurement shall also include sub-contracts to MSEs by large enterprises and consortia of MSEs formed by the National Small Industries Corporation (NSIC). It is suggested that government procurements from MSEs shall be reported in the respective annual reports indicating the goal and achievement. It is also suggested that all government organisations prepare an annual plan for procurement from MSEs, and upload the same on their official websites. Defence Production Policy including indigenisation of equipment and component manufacturing, and their implications for the MSME sector need to be kept in view on the greater role envisaged for the MSME sector. Platforms like vendor development programme organised periodically meet these objectives. They provide a unique opportunity to MSMEs to meet the requirements of Central PSUs/ Departments, and other large scale enterprises, and forge long term market linkages with them. The state governments have also been requested to evolve similar policies for the state PSUs. The programme is also bound to benefit large enterprises through identification of suitable vendors to outsource their requirements. This process can create sustainable market linkages for the MSE sector and result in improving the competitiveness of the sector. The concept of vendor development has increasing relevance in the manufacturing sector at present, due to increased competition both among large firms who source their requirements from small firms, and among supplier small firms themselves,.

\section{India SME Technology Services Ltd}

The Small Industries Development Bank of India (SIDBI) has set up a Technology Bureau for Small Enterprises (TBSE) at New Delhi in collaboration with the United Nations Asia-Pacific Centre for Transfer of Technology (UN-APCTT) to help SMEs tap the opportunities at the global level for acquisition of technology and establishing business collaborations. The TBSE, from its inception placed emphasis on networking to pool resources and enhance outreach so as to serve the technology related needs of small enterprises all over the 
country. The TBSE has since been converted into India SME Technology Services Limited (ISTSL) (in December 2005), for providing enhanced professional services for technology transfer, joint ventures, business collaboration, finance syndication, and attendant support services to the SMEs through a variety of technology facilitation services for promoting sustainable development.

\section{Fiscal Measures}

Under the general excise exemption scheme for micro and small enterprises, exemption limit for levying excise duty has been raised from Rs.1 crore to Rs.1.5 crore (in 2007-08 Union Budget), and the turnover eligibility limit to avail the exemption benefits has been enhanced from Rs.3 crore to Rs.4 crore (in 2005-06 Union Budget). Further, with effect from April 2005, small service providers having a turnover of up to Rs.4 lakh have been exempted from service tax. This exemption limit has been gradually raised to Rs.10 lakh in the subsequent budgets. In order to encourage SMEs to invest and grow, the surcharge on all firms and companies with a taxable income of Rs.1 crore or less has been removed with effect from April 2007.

\section{Development of Employment - intensive Enterprises}

Certain industries offer greater scope for labour-intensive technologies. These include agro and food processing industries, renewable energy development-based industries, and some product groups which have high export contribution such as gems and jewellery, electronic products, and others. Evolving policies and developing infrastructure needed for these industries for the benefit of producers and farmers in case of agro produce, will make a significant contribution to balanced regional development and employment generation on a large scale, and can promote inclusive growth.

Government is actively encouraging investment in agro and food processing industries to reduce wastage, and encourage value addition. The Eleventh Plan schemes aim at increasing government investment in creating the farm to market supply chain, and market processing infrastructure to attract more private investment. It is also proposed to strengthen Research and Development (R\&D), and Human Resource Development (HRD) in the food processing sector, establish more food testing laboratories to ensure quality of food products, and compliance of national and international standards, etc. The food processing sector employs 13 million people directly, and about 35 million people indirectly. Unorganised sector accounts for more than 70 per cent of production of the industry in terms of volume, and over 50 per cent in terms of value. On the export front, India has 1.5 per cent share of global processed food exports, despite its leadership in agricultural production. The Union Budget 2012-13 has announced the setting up of a National Mission on Food Processing in cooperation with the State Governments in the near future.

\section{Employment Generation Programmes for Micro Enterprises Promotion ${ }^{7}$}

Two recent schemes for helping first generation entrepreneurs for entrepreneurship development and employment generation are as follows: (i) Rajiv Gandhi Udyami Mitra Yojana (RGUMY), and (ii) Prime Minister's Employment Generation Programme (PMEGP).

RGUMY was launched in February 2008 for 'Promotion and Handholding of Micro and Small Enterprises', with the objective of helping and facilitating the potential first-generation entrepreneurs in completion of various formalities and tasks necessary for setting up and operationalisation of their enterprises. Candidates who have successfully completed entrepreneurship / skill development training of at least two weeks duration, or have undergone vocational training from industrial training institutes (ITIs) can take advantage of the scheme. Various lead entrepreneurship development agencies of the Centre and the State are associated with the implementation of the scheme as Udyami Mitras. In addition, non-governmental organisations, and industry associations are also urged to take over this role. Udyami Mitras are associated with the candidates at the stage of formulation of the project, getting it cleared for implementation, including obtaining finances from banks, and also after the establishment of the project for a minimum period of six months to monitor and follow up on the functioning of the enterprise, and provide help in overcoming managerial, financial and operational problems.

PMEGP is in operation from October 2008. This scheme which subsumes two schemes which were in operation up to the end of March 2008, namely, Prime Minister's Rozgar Yojana (PMRY) and Rural Employment Generation Programme (REGP), is much larger in coverage compared to the earlier schemes, and is applicable for rural and urban areas. The nodal agency at the national level for implementing the scheme is the Khadi and Village Industries Commission (KVIC), and at state and district level, the agencies associated with the implementation of the scheme are: KVIC, KVI Board, District Industries Centres (DICs) under the supervision of the Commissionerate of Industries, and banks. This is a credit linked subsidy scheme, with project cost excluding land, going up to (a) Rs.25 lakh for manufacturing, and (b) Rs.10 lakh for service and

${ }^{7}$ Union Ministry of MSME (2013), Annual Report 2012-13, New Delhi. 
business activities. The project cost includes capital expenditure excluding land, and one cycle of working capital. Subsidy as a proportion of the project cost given by the Government is $15 \%$ in the general category, and $25 \%$ in the special category in urban areas, and $25 \%$ in the general category, and 35\% in the special category in rural areas. The thrust of entrepreneurship development and employment generation of the scheme is on rural areas. Promoter's contribution envisaged is $10 \%$ in the general category, and $5 \%$ in the special category.

\section{Skill Development through the Micro and Small Enterprise Sector}

The Government has taken up skill development as a high priority area in the MSE sector through various measures like enhancing the training capabilities of the tool rooms, MSME - Development Institutes, and other organisations under the Ministry of MSME. The Skill Development Mission has been launched for which a Skill Development Corporation has been established at the national level under public-private partnership mode. Towards this endeavour, the agencies under the Ministry of MSME have been conducting training programmes. The Ministry's target is to enhance training capabilities of the existing organisations to 5 lakh trainees a year in the near future. Further, the Ministry of MSME provides all such training to the disadvantaged sections of the society like SCs / STs, free of cost. A number of programmes are also being organised for women, and other weaker sections of the society, free of cost, besides providing a monthly stipend of Rs.500 per month during the entire period of training. This endeavour is part of the National Action Plan for Skill Development, which aims at an ambitious goal of developing 50 crore (500 million) skilled and trained technicians in the country by 2020 . The banking community has been urged to think of innovative ways of financing to make skill acquisition by the youth a bankable proposition.

\section{Training and Entrepreneurship Development ${ }^{8}$}

Training for Entrepreneurship Development (ED) is one of the key elements for development of micro and small enterprises (MSEs), particularly, the first generation entrepreneurs. To undertake this task, the Ministry of MSME has set up three apex national level institutes. These are National Institute for Micro, Small and Medium Enterprises (NI-MSME), Hyderabad (Andhra Pradesh), Indian Institute of Entrepreneurship (IIE), Guwahati (Assam); and the National Institute for Entrepreneurship and Small Business Development (NIESBUD), NOIDA (Uttar Pradesh). Apex national level financial institutions promoted Entrepreneurship Development Institute of India (EDI) at Village Bhat, Gandhinagar District (Gujarat). Websites of these institutions are: www.nimsme.org; iie.nic.in; www.niesbud.nic.in; and www.ediindia.org, respectively. Entrepreneurship Development Centres / institutes have been established along with Industrial and Technical Consultancy Organisations, and MSME - Development Institutes at the state level. A number of nongovernmental organisations (NGOs) and industry associations have been helped in taking over the role of entrepreneurship training and counselling, and provision of escort services to trained candidates. The Union Ministry of MSME has been operating the scheme of assistance for strengthening the training infrastructure of existing and new entrepreneurship development institutes. The main objectives of the scheme are: (i) promoting entrepreneurship for creating self employment through enterprise creation; (ii) facilitating creation of training infrastructure; and (iii) supporting research on entrepreneurship related issues.

Further, in order to improve the success rate of the ED Programme trainees in the establishment of new enterprises, the Union Ministry launched a new scheme, Rajiv Gandhi Udyami Mitra Yojana (RGUMY) in 2008 - a scheme for promotion and handholding of micro and small enterprises. Details of the scheme are presented in section 13. The Ministry's website is www.msme.gov.in. Under this scheme, the 'Udyami Mitras' would provide guidance and assistance to potential entrepreneurs registered with them, in the preparation of project report, arranging finance, selection of technology, marketing tie-ups with buyers, installation of plant and machinery, as well as obtaining approvals, clearances and NOCs (no objection certificates), etc. The scheme is expected to provide an integrated and end-to-end support for the creation of new micro and small enterprises. For this purpose, the Udyami Mitras would be paid handholding charges under the scheme on per candidate basis. Another recent development is the Scheme of Partner Institutions (PIs) for Entrepreneurship Development (ED), being implemented from 2008 by the above mentioned apex Entrepreneurship Development Institutes through public-private partnership (PPP) mode. The scheme is known as Entrepreneurship Development Centres (EDCs) through partner institutions. A few more entrepreneurship development training institutions may take over this role in future. This scheme will enhance the outreach of these institutions, and at the same time, the partner institutions will also be benefited in terms of capacity building of their faculty, access to the infrastructure and resources of national level institutions through e-classes, etc. Through this approach, the partner instittions would be able to spread the entrepreneurship movement throughout the length and breadth of the country. The lead institutions provide training curriculum, high quality training material (including audio visual material), capacity building through training of PI's core faculty / trainers, and e - classes through video

${ }^{8}$ Ibid. 
conferencing, etc., and handholding facilities, after successful completion of the training courses, if needed. Through the PPP mode, it is planned to organise EDPs with focus on SC/ST/minority dominated remote and backward areas of the country. EDI offers distance learning programmes on Entrepreneurship and Small Business Management, and Management of Non-governmental Organisations. Development Education (International) Society (DEIS), Pune (Maharashtra) (website: www.deispune.org) is a recognised national resource centre in enterprise education and entrepreneurship development. It offers lessons in entrepreneurship education through audio and video programmes on All India Radio and Doordarshan, and publishes monographs on enterprise development.

\section{Conclusion and Suggestions}

The experience of recent years reveals that SMEs can gain through product innovation, diversification, and strategic diversion from slow growth traditional products to high value added growth products, and adoption of aggressive marketing strategies. Directions for the future can include: formation of consortia, cluster associations, and strategic alliances with their counterparts in other countries resulting in technological linkages, and financial tie-up. Special attention needs to be paid to promote research and development, quality assurance, innovation and incubation, and application of information technology tools. SMEs need to be supported with conducive policy environment for enabling them to make greater contribution to exports in a large way to achieve concrete results. Special focus has to be built on micro level planning of exports based on a smaller selective number of niche products (and services), niche locations including export clusters, and niche markets than has been attempted so far. While the government will have to play a crucial supportive role in carrying out the above exercise, the prime movers in the act will have to be exporting units themselves. Through periodic applied research and evaluation studies, it is important to make an assessment of the impact of certain policies on various product groups and in different regions of the country, and evolve new strategies relevant for coping up with the challenges of inclusive growth. SMEs in the competitive environment need to plan for globalisation as part of their strategy to enhance competitiveness, and not as a reaction to venture into new markets. Based on the experiences of recent years in the country and the recommendations of various studies, including the Prime Minister's Task Force on MSMEs, whose recommendations are currently being implemented, a few suggestions are made for improving the environment for SMEs in the globalisation context. Institutional framework and policy specifications are important factors in helping the evolution and success of SMEs.

1. Promoting Entrepreneurship and Skill Development: Private sector organisations and non-governmental organisations (NGOs) need to be involved to a greater degree with appropriate trainers' training programmes to equip them to shoulder the responsibility on PPP mode. The corporate sector may take the lead role in infusing enterprise education, skill upgradation, and management induction programmes. Promoting synergy is necessary to achieve integration in order to attain the desired goals by involving public sector and private sector organisations. Encouragement should be given for private corporate sector to establish business incubation support network, as also institutional framework and policy framework for business-turn around, for the benefit of SMEs.

2. Upgradation of Clusters and Creation of Value Chain: SMEs can achieve high level of competitiveness if they work in a cluster environment ensuring complementarities, common activities, and institutional stability. Collective innovations should flow from these efforts. Through strengthening of linkages and creation of value chain, clusters can be upgraded. These can include linkages among firms, strengthening the local position within the value chains, building cluster-specific skill centres to develop cluster-specific labour force, strengthening the linkages with the local suppliers, and facilitating greater level of interactions among the stakeholders of clusters.

3. Strengthening Sub-contracting Relationships within the Region / other Parts of the Country / Other Countries: Sustainability and growth of SMEs would largely depend on their capacity to become part of the strategies of larger firms in the national and global arena. This is particularly important for technology oriented and export-oriented SMEs, which serve as sub-contractors for large enterprises in sectors such as IT, biotech, pharmaceuticals, light engineering, electronics, and automobile components. SMEs should be equipped to meet the global standards and delivery mechanisms.

4. Focussed R\&D Institutions for SMEs: There is need for focussed institutions encouraging R\&D activities in the SME sector in a coordinated manner. They may identify thrust areas for research, new areas for technology application, opportunities for commercialisation of R\&D, and hand-holding of SMEs in their R\&D intensification. This can lead to higher level of technology intensive firms coming up in various product lines in thrust areas. 
5. Linking SME Strategy with Regional Trading Arrangements: Linking the SME development strategy with regional trading arrangements would encourage learnings from regional and cross-continental peer groups. Multi-national corporations (MNCs) may be encouraged to assist SMEs to upgrade them to meet quality standards that may be required by them. They should become SME-friendly by developing suitable tendering policies.

6. Increasing SMEs' access to Finance: The screening methodology of financing institutions needs to consider non-financial parameters and management competencies, while evaluating loan proposals of SME units. Export-Import Bank of India, Mumbai in collaboration with International Trade Centre, Geneva has implemented an unique enterprise management development services programme, which is an IT-based tool, loan.com to enable SMEs to prepare business plans with international market in focus. This is implemented as a pilot project for SMEs at present, and needs to be extended to more regions. The working group on credit flow to SMEs under the chairmanship of

K.C. Chakrabarty and the Prime Minister's Task Force on SMEs have suggested a number of measures for sustained development of the SME sector. These included establishment of a few funds in the SME sector for specific purposes. Action is to be initiated on a priority basis to implement these recommendations.

7. Pro-active Role of Industry Associations / Cluster Associations: It is suggested that the key associations at the state level / cluster associations at the cluster level should take the lead in implementing various programmes in the interest of their members. Pro-activeness from their side will enable the institutions concerned to perform in an appropriate manner, review the performance of a programme in various locations periodically, and bring out lessons for the future. Periodic monitoring and review of implementation of programmes is to be pursued regularly. Interaction across states is also necessary.

\section{References}

[1]. Export-Import Bank of India (2009), MSMEs and Globalisation: Analysis of Institutional Support Systems in India and in Select Countries, Occasional Paper No. 132 of the EXIM Bank, Mumbai. available at www. eximbankindia.in.

[2]. (2012),Strategic Development of MSMEs: Comparison of Policy Framework and Institutional Support Systems in

[3]. Government of India (2010), Report of the Prime Minister's Task Force on Micro, Small and Medium Enterprises (MSMEs), Prime Minister's Office, New Delhi (Chairman of the Task Force: T.K.A. Nair).

[4]. Government of India, Ministry of MSME (2013), Annual Report 2012-13, New Delhi, available at www.msme.gov.in.

[5]. Institute of Small Enterprises and Development (ISED) (2012), India Micro, Small and Medium Enterprises Report 2012 (MSMER 2012), ISED, Kochi (Kerala), available at www.isedonline.org.

[6]. Laghu Udyog Samachar (LUS) (Monthly Journal), published by Development Commissioner (MSME), New Delhi - Various Issues of 2009 - 2012, available at www.dcmsme.gov.in.

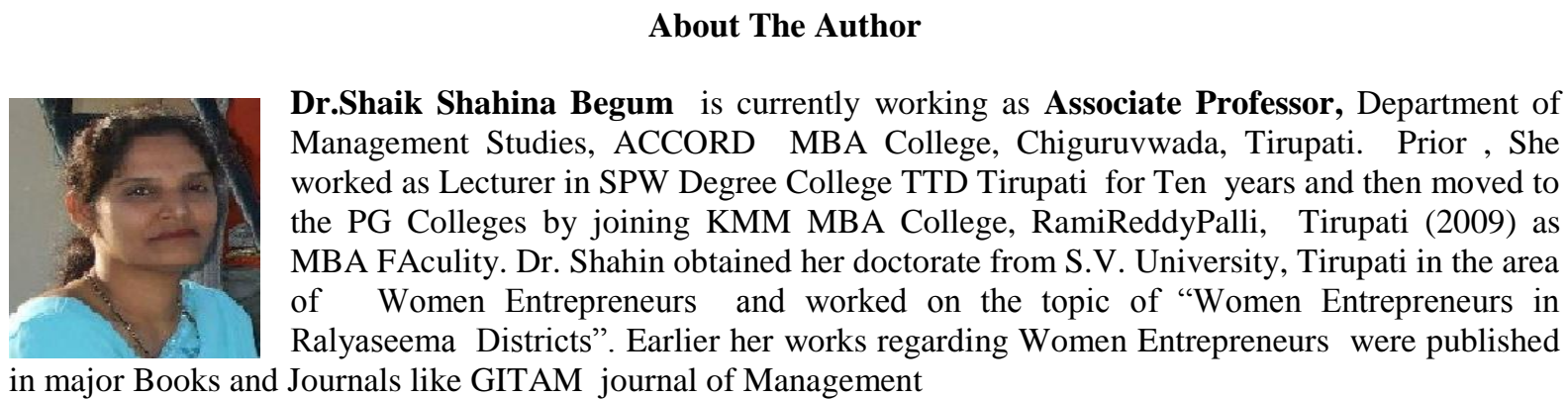

